\title{
Total diz protezi sonrasında görülen eklem sertliği
}

\author{
Joint stiffness after knee arthroplasty
}

\author{
Yasin Emre Kaya, Kutay Engin Özturan, Hüsamettin Çakıcı
}

Bolu Abant İzzet Baysal Üniversitesi Tıp Fakültesi, Ortopedi ve Travmatoloji Ana Bilim Dalı, Bolu, Türkiye

Primer diz protezi sonrası karşılaşılan komplikasyonlardan biri olan eklem sertliği hasta memnuniyetini ve yaşam kalitesini düşüren önemli bir komplikasyondur. Artrofibrozis, enfeksiyon, patellar komplikasyonlar, hasta uyumsuzluğu, heterotopik ossifikasyon, cerrahi teknikte yapılan hatalar ve komponent malpozisyonları eklem sertliği etiyolojisinin büyük çoğunluğunu oluşturur. Tedavinin planlanmasındaki temel adım eklem sertliğinin altında yatan sebebin belirlenmesinden geçer. Anestezi altında manipülasyon, artroskopik ya da açık artroliz ve revizyon cerrahisi tedavi seçenekleri arasındadır.

Anahtar sözcükler: eklem sertliği; artrofibrozis; komponent malpozisyonu; anestezi altında manipülasyon; artroliz
Joint stiffness, which is one of the complications encountered after primary knee arthroplasty, is an important complication that decreases patient satisfaction and quality of life. Arthrofibrosis, infection, patellar complications, noncompliance of patients, heterotopic ossification, mistakes made in the surgical technique and component malposition constitute the majority of the etiology of joint stiffness. The main step in planning treatment is determining the underlying cause of joint stiffness. Manipulation under anesthesia, arthroscopic or open arthrolysis and revision arthroplasty are among the treatment options.

Key words: joint stiffness; arthrofibrosis; component malposition; manipulation under anesthesia; arthrolysis

\section{T} otal diz protezi, diz osteoartritine (OA) bağlı ortaya çıkan ve hastanın yaşam kalitesini düşüren semptomların giderilmesinde kullanılan, kullanım sıklığı son yıllarda giderek artan ve başarısı kabul edilmiş bir cerrahi yöntemdir. Diz protezi ile temel olarak ağrıyı ortadan kaldırmak ve hastanın günlük aktivite ihtiyaçlarını giderebilecek stabil bir diz eklemi oluşturmak amaçlanır. Yapılan biyomekanik çalışmalar ve yürüme analizleri göstermiştir ki, kişi yürüme döngüsünün topuk vuruşu esnasında dizin neredeyse tam ekstansiyonuna; salınım fazı için $67^{\circ}$, merdiven çıkabilmek için $83^{\circ}$, merdiven inebilmek için $90^{\circ}-100^{\circ}$, standart yükseklikteki bir sandalyeden kalkabilmek için $93^{\circ}$, daha alçak bir sandalyeden kalkabilmek için $105^{\circ}$ asgari diz fleksiyonuna ihtiyaç duyar. ${ }^{[1]}$

Total diz protezi sonrasında asgari düzeyde bu ihtiyaçları karşılayabilecek eklem hareket açıklığının (EHA) sağlanabilmesi hedeflense de geçmişten günümüze diz protezi sonrası eklem sertliği diğer komplikasyonlara göre rölatif olarak sık karşılaşılan bir komplikasyon olarak bildirilmektedir. Tarihsel süreçte, diz protezi sonrası eklem sertliği tanımlanırken "maksimum diz fleksiyon değeri, maksimum hareket arkı değeri, fleksiyon kontraktürünün görüldüğü değer” gibi çeşitli ölçümler kullanılmıştır. Literatürde görülme sıklığı \%1,3 ila \%60 arasında oldukça geniş̧ bir aralıkta bildirilmiştir. Literatürde insidansın bu kadar çeşitli bildirilmesinin sebebi, tanı kriterleri konusunda net bir görüş birliğinin olmamasıdır. Protez ameliyatı sonrası diz fleksiyonunun $90^{\circ}$ üzerine çıkarılması, hastanın temel günlük aktivitelerini gerçekleştirebilmesi açısından kabul görmüş bir amaçtır. Bu kriter göz önüne alınarak literatüre bakıldığında insidans \%3,7-6,3 aralığında görülmektedir. ${ }^{[2]}$

\section{ETIYOLOji}

Diz protezi sonrası gelişen eklem sertliğinin etiyolojisi; ameliyat öncesi durumlar, ameliyat sırasında kullanılan implant tasarımı ve cerrahi tekniğe bağı durumlar, ameliyat sonrası rehabilitasyon ve gelişebilecek diğer komplikasyonlar ile ilişkisi şeklinde incelenecektir.

İletişim / Contact: Dr. Öğr. Üy. Yasin Emre Kaya • E-posta / E-mail: yemrek@hotmail.com

ORCID iD: Yasin Emre Kaya, 0000-0002-5412-8355 • Kutay Engin Özturan, 0000-0001-9506-4370 • Hüsamettin Çakıcı, 0000-0003-2153-7774 


\section{Ameliyat Öncesi Durumlar}

Literatürdeki birçok çalışma hastanın ameliyat öncesi eklem hareket açıklığının ameliyat sonrası elde edilecek eklem hareket açıklığına etki edecek en önemli değişken olduğunu ortaya koymaktadır. ${ }^{[3]}$ Ameliyat öncesinde opere edilecek dizin fleksiyon ve ekstansiyon ölçümleri dikkatli bir şekilde yapılmalı ve kayıt altına alınmalıdır. Anouchi ve ark., yaptıkları çalışmaya göre çoğu hastada total diz protezi (TDP) ameliyatı sonrası diz fleksiyonu değerinin, ameliyat öncesi değere göre ortalama olarak $10^{\circ}-15^{\circ}$ artış göstereceğini bildirmişlerdir. ${ }^{[4]}$ Bu genellemenin yanında dikkat edilmesi gereken bir hususa Harvey ve ark. dikkat çekmişlerdir. Yaptıkları çalışmada elde ettikleri sonuçlara göre, ameliyat öncesinde düşük fleksiyon derecesine $\left(<90^{\circ}\right)$ sahip hastaların ameliyat sonrası fleksiyon derecelerinde artış olduğunu; bunun yanında ameliyat öncesinde yüksek fleksiyon derecesine $\left(>105^{\circ}\right)$ sahip hastaların fleksiyon değerinde azalma olduğunu, fakat bu hastaların sonuç itibarı ile diğer gruba göre daha yüksek değerlere ulaştıklarını bildirmişlerdir. ${ }^{[5]}$

Dizde oluşan OA'nın sebebi ve ameliyat sonrası eklem sertliği arasında ilişki de literatürde değerlendirilmiş̧ir. Lee ve ark., çalışmalarında ameliyat öncesi var olan eklem sertliğinin ameliyat sonrası EHA ile ilişkili olduğunu ortaya koymuşlardır. Ameliyat öncesinde şiddetli eklem sertliği olan (EHA $<50^{\circ}, 18 \mathrm{diz}$ ) ve orta derecede eklem sertliği olan (EHA $50^{\circ}-90^{\circ}$ aralığında, $104 \mathrm{diz}$ ) grubu karşılaştırmış, ameliyat öncesinde şiddetli eklem sertliği olan grupta ameliyat sonrasında ortalama $47^{\circ} \mathrm{EHA}$ kazanımı olduğunu, orta derecede eklem sertliği olan grupta $27^{\circ} \mathrm{EHA}$ kazanımı olduğunu bildirmişlerdir. Aynı çalışmada primer OA ve enflamatuvar artrit sonrası protez yapılan dizlerde, EHA kazanımının enfeksiyöz ya da travmatik artrit sonrası protez yapılan dizlere göre daha yüksek olduğu sonucuna ulaşmışlardır. ${ }^{6]}$

Literatüre bakıldığında öncesinde geçirilmiş diz cerrahisi ve buna bağlı skar ya da keloid oluşumu, obezite, diabetes mellitus (DM), yaş, cinsiyet gibi faktörler ile ameliyat sonrası EHA'nın ne denli ilişkili olduğuna dair üniversal kabul görmüş bir fikir birliği olmadığı görülmektedir. Literatürde tek seansta bilateral diz protezi uygulamasının, ayrı günlerde yapılan bilateral diz protezi uygulamasına göre eklem sertliği insidansını artırdığı yönünde çalışmalar olsa da bunun aksini ortaya koyan çalışmalar da mevcut olup, bu konuda da görüş birliği mevcut değildir. ${ }^{[7]}$

Cerrahi yapılacak hastanın uyumlu ve psikolojik olarak pozitif olması, sonrasında uygulanacak olan rehabilitasyonun başarısı için oldukça önemlidir. Depresif ve ağrı eşiği düşük olan hastaların rehabilitasyonu zordur ve bu hastalar eklem sertliği için adaydırlar. ${ }^{[8]}$
Cerrahi öncesinde hastayı bilgilendirmekten ziyade, cerrahi sonrası rehabilitasyonun önemini anlatmak ve bu konuda hastaya eğitim vermek ameliyat sonrası gelişebilecek eklem sertliği riskini düşürebilmektedir. ${ }^{[9]}$

\section{Kullanılan İmplant ve Cerrahi Tekniğe Bağlı Durumlar}

Ameliyat esnasında kullanılan implantların tasarımı, uygulanan cerrahi teknikteki hatalar ameliyat sonrası eklem sertliğine neden olabilmektedir. Fleksiyonekstansiyon aralığında dengesizlik, komponentlerin malpozisyonu ya da olması gerektiğinden büyük ya da küçük seçilmesi, yetersiz tibial ya da femoral rezeksiyon, eklem çizgisinin fazla elevasyonu, anterior tibial eğim oluşturulması, posterior osteofitlerin yetersiz rezeksiyonu fleksiyon kısıtlılığına ya da kontraktürüne sebep olabilmektedir. ${ }^{[10]}$

Özellikle sagittal planda gözlenen komponent malpozisyonu fleksiyon ve ekstansiyon kısıtlılığı yaratabilmektedir. Femoral komponent sagittal planda femurun özellikle distal yarısının anatomik aksına uygun yerleştirilmelidir. Olması gerektiğinden daha fazla fleksiyon pozisyonunda yerleştirilmesi ekstansiyon kısıtlıı̆̆ına, ekstansiyon pozisyonunda yerleştirilmesi fleksiyon kısıtlılığına yol açabilir. ${ }^{[10]}$

Tibial komponentin sagittal plandaki malpozisyonu da hareket kısıtlılığına sebep olabilir. Sagittal planda tibia plato anatomisinde görülen posterior eğim, yapılan tibia kesisi ile de oluşturulmalıdır. Yapılan tibia kesisi ile anterior eğim oluşturulursa, yani sagittal planda posterior korteks anteriora göre daha yüksekte kalırsa posteriordaki eklem aralığı daralır ve bu da fleksiyon kısıtlıı̆̆ına yol açabilir. Arka çapraz bağın (AÇB) korunduğu protez uygulamalarında bu problem bir miktar daha ön plana çıkabilmektedir. ${ }^{[10]}$

Komponentlerin fazla iç ya da dış rotasyonda olması da ameliyat sonrası eklem hareketini kısıtlayabilen bir diğer problemdir. Tibial komponentin fazla iç rotasyonda yerleştirilmesi, medial kollateral ligamentin (MKL) gerginliğinde artış, patellar maltracking, fleksiyonda medial aralıkta gerginlik, lateral tibial kondil üzerinde oluşan femoral rollback hareketinde azalma ve bunlara bağlı eklem hareketinde olası kısıtlılık ve ağrı ile ilişkilendirilmiştir. ${ }^{[11]}$ Bilgisayar programı ile yapılan simülatif bir çalışmada tibial malrotasyonun çömelme hareketi esnasında MKL ve lateral kollateral ligament (LKL) üzerindeki traksiyon kuvvetleri üzerine etkisi incelenmiş, MKL'de iki kat fazla olmak üzere ve hem LKL'de hem de MKL'de traksiyon kuvvetinin arttığı bildirilmiş ve bu durum olası eklem sertliği ile ilişkilendirilmiştir. ${ }^{[12]}$

Cerrahi sırasında kemik kesileri yapıldıktan sonra yerleştirilecek implantlar için yeterli ölçüde fleksiyon, 
ekstansiyon ve patellofemoral boşlukların oluşturulmuş olması gerekir. Aksi takdirde hem fleksiyonda hem de ekstansiyonda kısıtlılık görülebilir. Distal femur ya da proksimal tibia kesilerinin yetersiz olması ekstansiyon sıkılığına sebep olur. Uygulanacak olan femoral komponentin anteroposterior çapının, kişinin femur çapından büyük seçilmesi ya da tibial kesinin posterior yerine anterior eğimli olması da fleksiyon sıkılığına sebep olacaktır. Patellar implant kullanılacak ise patelladan rezeke edilen kıkırdak ve kemik kalınlığı toplamı yerleştirilecek olan implantın kalınlığını geçmemelidir. Aksi takdirde patellofemoral boşluk patellar implantın yerleştirilmesi ile birlikte fazla sıkı olacaktır. Bu boşlukların doğru olarak değerlendirilebilmesi için anestezi ile sağlanan tam kas gevşemesinin olması gerektiği akıldan çıkarılmamalıdır. Tüm bunların yanı sıra kullanılacak insertin olması gerektiğinden daha kalın seçilmesi de hem fleksiyon hem de ekstansiyon gerginliğine sebep olabilir. ${ }^{[13]}$

Femoral komponentin kişinin kendi femur anteroposterior çapından küçük seçilmesi ile hem posterior offset azalır hem de femur posterioru femoral komponent tarafindan tam kaplanamaz. Posteriorda komponentin örtmediği kısım impingement yapabilir. Hem impingement hem de posterior offsetin azalması fleksiyonu kısıtlayabilir. ${ }^{[13]}$

Femur ve tibianın arkasındaki osteofitlerin temizlenmemesi fleksiyon ve ekstansiyon kısıtlılığına sebep olabilir. Posteriorda bırakılmış osteofitler fleksiyonda tibial inserte değerek fleksiyonu, ekstansiyonda posterior kapsülün gerilmesine sebep olarak ekstansiyonu kısıtlayabilir. ${ }^{[13]}$

Cerrahi esnasında tibia ve femur kesilerinin yapılmasıyla birlikte olması gerektiğinden daha yüksekte bir eklem seviyesi oluşturulursa, bu rölatif olarak bir patella baja durumunun ortaya çıkmasına sebep olur ve bu durum da fleksiyon kısıtlılığına sebep olabilir. Konu ile ilgili yapılan bir çalışmada eklem seviyesinde $10 \mathrm{~mm}$ yükselmenin ciddi fleksiyon kısıtlılığına sebep olabileceği bildirilmişken ${ }^{[14]}$, bir diğer çalışmada bu değer 16 $\mathrm{mm}$ olarak bildirilmiştir. ${ }^{[15]}$

Bağ koruyan protez kullanımında eğer AÇB fazla gergin ise diz fleksiyonunu kısıtlayabilir. $20^{\circ}$ 'nin üzerindeki fikse varus deformitelerde $A$ ÇB'nin rezeksiyonu ya da gevşetilmesi gerekir. AÇB'nin fazla gevşek olması ise femurun anterior translasyonuna, bu da ekstansör mekanizmada impingementa sebep olabilir. Yapılacak AÇB rezeksiyon ya da gevşetmelerinde bu akıldan çıkarılmamalıdır. ${ }^{[16]}$

Singleton ve ark., yaptıkları ileriye dönük çalışmada bağ koruyan (CR) ya da posterior stabilize (PS) tasarımlı diz protezi ile tedavi edilmiş hastaların ameliyat sonrası fonksiyonel kazanımlarını mukayese ettiklerinde eklem sertliği açısından ilk bir yıl içerisinde PS protezlerle tedavi edilen grubun daha iyi sonuçlara sahip olduğunu fakat beş yıl sonunda bu farkın ortadan kalktığını bildirmişlerdir. ${ }^{[17]}$

Cerrahi sonunda kapsül ve fasyanın diz fleksiyonda iken sütüre edilmesi ekstansör mekanizmanın gerginliğini azaltarak cerrahi sonrası dönemde fleksiyon açıklığına katkıda bulunabilir. Bununla ilgili literatürde üniversal bir kabul yoktur. ${ }^{[18]}$

\section{Ameliyat Sonrası Rehabilitasyon ve Gelişebilecek Diğer Komplikasyonlar ile iliş̧kisi}

Ameliyat sonrası gelişebilecek komplikasyonlar kazanılmak istenen EHA'yı olumsuz etkileyerek eklem sertliğine sebep olabilir. Bunların başlıcaları derin enfeksiyon, artrofibrozis, patellar komplikasyonlar, kompleks rejyonel ağrı sendromu (KRAS) ve heterotopik ossifikasyondur (HO). ${ }^{[9]}$

Total diz protezi sonrası derin enfeksiyonlar belirgin eklem sertliğine sebep olabilir. Eğer ki cerrahi sonrası istenilen EHA'ya ulaşılmış ve sonrasında aniden kısıtlılık gelişmiş ise mutlaka enfeksiyon göz önüne alınmalı ve ekarte edilmelidir. ${ }^{[10]}$

Patella ile ilgili komplikasyonlar ağrıya yol açar ve hasta ağrı oluşumunu engellemek amacıyla diz hareketlerini kısıtlayabilir. Patella yüzeyi değiştirilmiş ise gevşeme ve maltracking açısından özellikle değerlendirilmelidir. Eğer yüzey değiştirilmemiş ise olası bir kırık ya da patellanın artrozu ağrıya ve eklem sertliğine sebep olabilir. ${ }^{[10]}$

Kompleks rejyonel ağrı sendromu diz protezi sonrasında oldukça nadir görülen bir komplikasyondur; yaklaşık \%0,8 oranında görüldüğü bildirilmiştir. Şiddetli ağrı, eklem çevresindeki cilt duyusunda bozulma, hareket kısıtlılığ ve vazomotor bozukluklar ile seyreder. KRAS sonrası gelişen eklem sertliğinin fonksiyonel iyileşmesinin tatmin edici olmadığı bildirilmiştir. Tedavisinde sempatik blokaj ve fizik tedavi önerilmektedir. ${ }^{[19]}$

Heterotopik ossifikasyon diz protezi sonrası \%3,8-26 aralığında bildirilmiştir. Sıklıkla suprakondiler bölgede ve suprapatellar poşta görülür. Bulunma yeri ve miktarının eklem sertliğinin şiddeti ile orantısının olmadığı bilinmektedir. Tedavisi eksizyon ve fizik tedavidir. ${ }^{[20]}$

Artrofibrozis eklem sertliğinin en sık sebebidir ve insidansı \%1,2-17 aralığında bildirilmiştir. Özellikle ekstansör mekanizma ve anterior femoral korteks arasında, medial ve lateral boşluklarda ilerleyici bir şekilde bol miktarda skar (nedbe) dokusu oluşur ve bu boşlukları doldurarak yapışıklıklara sebep olur. ${ }^{[21]}$

Bu komplikasyonların dışında hastanın rehabilitasyona uyumu oldukça önemlidir. Uyumsuz ve ağrı eşiği 
düşük olan hastalar eklem sertliği için adaydırlar. Bu tip hastaların eğitimi ve motive edilmesi eklem sertliği gelişimini azaltabilir. ${ }^{[9]}$

\section{TEDAVi}

Diz protezi sonrasında eklem sertliği ile mücadelenin ilk basamağı gerekli önlemlerin alınmasından geçer. Cerrahi sonrası yapılacak olan erken dönem rehabilitasyon programı ve hastanın bu programa uyumu özenle takip edilmelidir. Cerrahi sonrası vakit kaybedilmeden, hemen pasif ve aktif diz eklem hareketlerine başlanmalıdır. Bu program en az 15 gün sürmeli ve hatta mümkünse daha da uzatılmalıdır. Shoji ve ark., cerrahi sonrasında bir ay düzenli rehabilitasyon alan hastaların, cerrahi sonrasında 14 gün düzenli rehabilitasyon alan hastalara göre dokuz yıllık takiplerde daha iyi diz fleksiyonuna sahip olduklarını bildirmişlerdir. ${ }^{[15]}$

Cerrahi sonrasında gelişen eklem sertliğinin altında yatan sebebin ortaya konması tedavi planının temel unsurudur. Eklem sertliği tanısı konduktan sonra eğer enfeksiyon ekarte edilmişse, implant pozisyonları ve cerrahi teknikle ilgili eklem sertliğini açıklayacak bir problem yoksa ve yeterli ağrı kesiciler eşliğinde agresif bir rehabilitasyona cevap alınamıyorsa ileri tedavi gerekebilir. Bu durumda tedavide kullanılan yöntemler anestezi altında manipülasyon (AAM), açık ya da artroskopik artroliz ve revizyon cerrahisidir.

\section{Anestezi Altında Manipülasyon (AAM)}

Anestezi altında manipülasyon seçilecek ilk yöntem olarak karşımıza çıkmaktadır. Tedavide oldukça sık olarak kullanılmasına rağmen prosedürün ideal zamanlaması, hangi hastalarda daha çok kazanım olacağı ve tekrarlanan manipülasyonların etkinliği ile ilgili genel bir görüş birliği yoktur. ${ }^{[18]}$

Son dönemlerde femoral ve siyatik sinir blokları altında manipülasyonlar tarif edilmiş olsa da genel olarak kabul edilen genel ya da rejyonel anestezi altında tam kas gevşemesi ile birlikte yapılan uygulamadır. Anestezi sonrası kalça $90^{\circ}$ fleksiyona alınır ve tibia proksimal kısmından tutulur. Daha distalden ya da ayak bileği seviyesinden tutmak, istenmeden fazla ve ani tork uygulanmasına ve buna bağlı komplikasyonlara sebep olabilir. Yapışıklıkların açılmasına bağlı ses duyulana kadar ve palpasyonla hissedilene kadar kontrollü ve sabit bir kuvvetle diz fleksiyona zorlanır. Burada amaçlanan eklem içinde ve çevresindeki skar dokusunun plastik deformasyona uğramasıdır ve bu birkaç dakika sürebilir. Skar dokusunun gevşemesiyle birlikte uygulanan aynı kuvvetle birlikte diz fleksiyonunda bir noktaya kadar artış olacaktır. Son gelinen noktadan sonra çok fazla zorlamak yerine bu işlemi birkaç kez tekrar etmek önemlidir. Yer çekimi etkisiyle, ilk başta kuvvet uygulayarak gelinen fleksiyon derecesine gelindiğinde işlem sonlandırılır. ${ }^{[22]}$

Manipülasyon sonrası eklem hareket açıklığında beklenen artış $38,4^{\circ}$, diz fleksiyonunda artış 29,4 $4^{\circ}$ olarak bildirilmiştir. ${ }^{[23]}$ AAM sonuçları hem işlem sonrası erken dönemde hem de uzun dönem takipleri sonrasında yüz güldürücü bulunmuştur. Bazı çalışmalar, AAM sonrası elde edilen eklem hareket açılığının uzun dönem takipleri sonunda değişmediğini bazıları ise azaldığını bildirmişlerse de elde edilen son değerin AAM öncesine göre yüksek olduğunu vurgulamışlardır. ${ }^{[24]}$

Ameliyat öncesi ve ameliyat anında karşılaşılan faktörler AAM başarısını etkileyebilir. Bağ koruyan protez kullanılmış olması, diabetes mellitus varlığı ve dizin ikiden daha fazla cerrahi geçirmiş olması ile AAM başarısının azaldığı bildirilmiştir. ${ }^{[25]}$

Literatüre bakıldığında manipülasyonun ne zaman yapılacağı konusunda birçok ayrı görüş mevcuttur. Erken veya geç manipülasyon kavramları kimi yazarlara göre 30 gün öncesi ve sonrası, kimisine göre 12, hatta 20 hafta olarak kabul edilmiştir. Başlardaki çalışmalar cerrahiden iki hafta sonra fleksiyon $90^{\circ}$ 'nin altında ise AAM yapılmasını önermişlerdir. ${ }^{[15]}$ Daha sonra yapılan çalışmalarda cerrahiden 12 hafta sonra yapılan manipülasyonun klinik sonuçlarının benzer olduğu ortaya konmuştur. ${ }^{[26]}$ Son dönemlerde bu konu ile ilgili bir fikir birliği oluşturulmaya çalışılmış ve buna göre cerrahi sonrası üç ila altı ay arasında başarıyla uygulanabileceği ve altı ay sonrasında endike olmadığı bildirilmiş̧tir. [27]

Illk yapılan AAM sonrasında beklenen ilerleme gözlenmeyen hastalarda işlemin tekrar yapılması gündeme gelmiştir. Yapılan çalışmalarda hastaların hemen hemen yarısında tatmin edici sonuçlara ulaşılmış, diğer yarısında artroliz ya da revizyon cerrahisine ihtiyaç duyulduğu bildirilmiştir. ${ }^{[28]}$

Anestezi altında manipülasyon sonrası komplikasyonlar oldukça nadir olarak görülmektedir ve literatürdeki sıklığı \%0,88 olarak bildirilmiştir. Literatürde periprostetik kırık, hemartroz, pulmoner emboli, subdural hematom ve yara ayrışması şeklinde bildirilmiştir. Periprostetik kırık, ileri osteoporozlu hastalarda fazla uygulanan kuvvet ile ilişkilendirilirken, yara ayrışması ise ilk 10 gün içerisinde yapılan manipülasyonlar ile ilişkilendirilmiştir. ${ }^{[29]}$

Anestezi altında manipülasyon sonrasında mutlaka programlı bir rehabilitasyona devam edilmelidir. Güçlü analjezi desteği rehabilitasyon başarısını artıran önemli bir faktördür. Manipülasyon sonrasında epidural 
yolla sağlanan analjezi ile birlikte sonuçların oldukça iyi olduğu bildirilmiştir. ${ }^{[30]}$ Manipülasyon sonrası diz içerisine lokal anestetik ve kortikosteroid uygulanması da bir analjezi yöntemi olarak seçilmiş olsa da bu yöntemin enfeksiyon kaynağı olabileceği akıldan çıkarılmamalıdır. ${ }^{[31]}$

\section{Artroskopik Artroliz}

Altı ila on iki ay boyunca uygun rehabilitasyon uygulanmasına rağmen ilerleme görülmüyor ise cerrahi prosedürler düşünülmelidir. Cerrahi tedavi ise eklem sertliğinin altında yatan etiyolojiye yönelik olmalıdır. Artroskopik artroliz ile eklem içerisindeki yapışıklıkların giderilmesi amaçlanır ve artrofibrozis gelişen hastalarda rehabilitasyon ve manipülasyona rağmen ilerleme sağlanamadığında seçilebilecek cerrahi bir yöntemdir. Üç ila altı ay boyunca tüm konservatif tedavilere rağmen ilerleme görülmeyen, artrofibrozise bağlı ağrısız eklem sertliklerinde başarı oranının yüksek olduğu bildirilmiştir. ${ }^{[32]}$

Cerrahide genellikle klasik medial ve lateral portaller yeterli olur. Suprapatellar aralığa ulaşım kolaydır ve buradaki adhezyonların giderilmesi ile fleksiyon kazanımı daha ön planda olacaktır. Medial ve lateral boşluklardaki fibrotik dokular eksize edilebilir. Bağ koruyan protezlerde gergin AÇB artroskopik olarak gevşetilerek fleksiyon aralığı artırılır. Bunun yanı sıra eklemin posterioruna ulaşmak neredeyse imkânsızdır, dolayısı ile ekstansiyon kazanımı açısından etkinliği oldukça azdır. Ancak var olan anterior cyclops lezyonu ya da menisküs kalıntısı temizlenerek ekstansiyona katkı sağlanabilir. Serbest kalmış sement parçaları çıkarılabilir. Aynı zamanda dokulardan mikrobiyolojik ve histopatolojik inceleme için örnek alınabilir. Patellofemoral yapışıklıkların daha kolay gevşetilebilmesi için superomedial ve superolateral portaller eklenebilir. [33]

Literatüre bakıldığında artroskopik artroliz sonrası eklem hareket açıklığndaki kazanımlar genellikle olumlu yönde olmakla birlikte çeşitlilik göstermektedir. Çalışmalarda genel olarak $30^{\circ}$ civarında eklem hareket açıklığı kazanımı bildirilmiştir. İzole patellofemoral fibrozis varlığında en iyi sonuçların elde edildiğine dair görüş birliği mevcuttur. Eklem hareket açıklığının $60^{\circ}$ 'nin altında olduğu ciddi eklem sertliği görülen olgularda sonuçların kötü olduğu bildirilmiştir. ${ }^{[34]}$

Birçok yazar artrolizin altı aydan daha uzun süre ertelenmemesi gerektiğini aksi takdirde skar dokusunun sertleşmesi nedeniyle cerrahi başarının düşeceğini ileri sürmüşlerdir. Cregar ve ark. ise genç hastalarda daha sık artroliz gerektiğini ve TDP sonrası bir yıl içerisinde artroliz yapılan hastaların revizyon artroplastisi için yüksek risk taşıdıklarını ifade etmişlerdir. ${ }^{[35]}$

\section{Açık Artroliz}

Total diz protezi ameliyatı sonrasında altı ay süre ile diğer konservatif tedavilere cevap vermeyen ve ciddi hareket kısıtlılığı görülen artrofibrozis olgularında endikedir. Suprapatellar poş, medial ve lateral boşluklar eksplore edilmeli, fibröz bantlar gevşetilmeli ve uzaklaştırılmalıdır. Eksplorasyonun daha iyi hale getirilmesi için posteromedial köşenin öncelikle gevşetilmesi önerilmektedir. Patellanın eversiyonu sağlanamaz ise tibial tüberkül osteotomisi (TTO) ya da kuadriseps tendonuna snip ya da V-Y plasti gerekebilir. Ekstansiyonu artırmak için posterior yapılar gevşetilmelidir. TTO yapılmış ise 1 ya da $2 \mathrm{~cm}$ proksimale transfer edilmesi patellayı eleve ederek ve ekstansör gerginliği azaltarak fleksiyon kazanımına sebep olur. Kuadriseps tendonunda yapılacak uzatma ekstansiyon gücünü ve miktarını azaltmadan fleksiyona katkı sağlayacaktır. ${ }^{[6]}$ Patellofemoral aralık gerginse patellar rezeksiyon yapılabilir. Açık artroliz ile birlikte gerekli durumlarda tibial insert daha incesi ile değiştirilebilir. ${ }^{[10]}$

\section{Revizyon Cerrahisi}

Eklem sertliğine neden olan sebepler primer cerrahiye bağı hatalar, implant seçimi ya da malpozisyonu ile ilgiliyse revizyon cerrahisi düşünülmelidir. Revizyon yapmadan önce mutlaka primer protezde yapılan hataların fark edilmesi ve bunların giderilebilmesi için revizyonun planlanması gerekir. Dikkatli özene ve planlamaya rağmen sonuçları tamamıyla öngörmek mümkün olmayabilir. ${ }^{[37]}$

Tekrar yapılacak kesiler sebebiyle fibrozis yeniden tetiklenebilir. Hâlihazırda var olan fibrozis ile patellar tendon kısalmış olabilir ve bu da patellar tendon avülsiyonuna sebep olabilir. Bundan kaçınmak için açık artrolizde bahsettiğimiz TTO, kuadriseps snip ya da $\mathrm{V}-\mathrm{Y}$ plasti gerekli olabilir. Yine açık artrolizde bahsettiğimiz üzere fibröz dokunun eksizyonu mümkün olduğunca geniş bir şekilde yapılmalıdır. Yeterli gevşetmeler yapıldıktan ve yeterli görüş alanı sağlandıktan sonra komponent stabilitesi, komponentlerin pozisyonları, eklem seviyesi, polietilen aşınması, patellofemoral uyum, yumuşak doku dengesi dikkatli bir şekilde kontrol edilmelidir. ${ }^{13,36]}$

Patellaya ait problemler dikkatle gözden geçirilmelidir. Belirgin şekilde eklem sertliğine sebep olması sebebiyle patella kalınlığı ölçülmeli, eğer gerekli ise rezeksiyon yapılmalıdır. Yumuşak doku dengesi hem ekstansiyonda hem de fleksiyonda sağlanmalıdır. ${ }^{[13]}$

Bilindiği üzere eklem sertliği yeniden eklenecek olan fibröz dokular ile birlikte tekrarlayabilir. Eklem sertliğine bağlı gerçekleştirilen revizyon cerrahilerinde bu 
durum göz önünde bulundurulmalıdır. Buna istinaden ekstansiyonda bir miktar laksite medialde ve lateralde eşit seviyede olmak üzere tercih edilebilir. Eklem sertliği rekürrensi göz önünde bulundurularak revizyon protezde $5^{\circ}$ hiperekstansiyon oluşturmak tercih edilebilir. ${ }^{[38]}$ Koronal, aksiyel ve sagittal planda komponent malpozisyonları düzeltilmeli, eklem seviyesi uygun şekilde ayarlanmalıdır. ${ }^{[13]}$

Rutherford ve ark., TDP sonrasında artrofibrozise bağlı gelişen eklem sertliğinin tedavisi için yapılan revizyon protezlerinde çoğunlukla eklem hareket açıklıklarında önemli iyileşme sağlandığını fakat serilerinde hastaların \%30'unda revizyon protezi sonrasında eklem hareket açıklı̆ında azalma olduğunu bildirmişlerdir. ${ }^{[39]}$ Sınırlı yaklaşım (yumuşak doku gevşetmesi ve insert küçültülmesi) ile total revizyon olgularının mukayese edildiği bir diğer çalışmada EHA kazanımı ile fonksiyonel skorların total revizyonda belirgin ölçüde yüksek olduğu bildirilmiştir. ${ }^{[40]}$

\section{KAYNAKLAR}

1. Laubenthal KN, Smidt GL, Kettelkamp DB. A quantitative analysis of knee motion during activities of daily living. Phys Ther 1972;52(1):34-43. Crossref

2. Gandhi R, de Beer J, Leone J, Petruccelli D, Winemaker M, Adili A. Predictive risk factors for stiff knees in total knee arthroplasty. J Arthroplasty 2006;21(1):46-52. Crossref

3. Ritter MA, Harty LD, Davis KE, Meding JB, Berend ME. Predicting Range of Motion After Total Knee Arthroplasty. J Bone Joint Surg Am 2003;85(7):1278-85. Crossref

4. Anouchi YS, McShane M, Kelly F Jr, Elting J, Stiehl J. Range of motion in total knee replacement. Clin Orthop Relat Res 1996;331:87-92. Crossref

5. Harvey IA, Barry K, Kirby SP, Johnson R, Elloy MA. Factors affecting the range of movement of total knee arthroplasty. $J$ Bone Joint Surg Br 1993;75-B(6):950-5. Crossref

6. Lee SA, Kang S-B, Chang CB, Chang MJ, Kim YJ, Song MK, Jeong $\mathrm{JH}$. Does the severity or cause of preoperative stiffness affect the clinical results and range of motion after total knee arthroplasty? PLoS One 2018;13(10):e0205168. Crossref

7. Meehan JP, Monazzam S, Miles T, Danielsen B, White RH. Postoperative Stiffness Requiring Manipulation Under Anesthesia Is Significantly Reduced After Simultaneous Versus Staged Bilateral Total Knee Arthroplasty. J Bone Joint Surg Am 2017;99(24):2085-93. Crossref

8. Fisher DA, Dierckman B, Watts MR, Davis K. Looks good but feels bad: factors that contribute to poor results after total knee arthroplasty. J Arthroplasty 2007;22(6 Suppl 2):39-42. Crossref

9. Livbjerg AE, Froekjaer S, Simonsen O, Rathleff MS. Preoperative patient education is associated with decreased risk of arthrofibrosis after total knee arthroplasty: a case control study. J Arthroplasty 2013;28(8):1282-5. Crossref

10. Bong MR, Di Cesare PE. Stiffness after total knee arthroplasty. J Am Acad Orthop Surg 2004;12(3):164-71. Crossref

11. Bédard M, Vince KG, Redfern J, Collen SR. Internal rotation of the tibial component is frequent in stiff total knee arthroplasty. Clin Orthop Relat Res 2011;469(8):2346-55. Crossref
12. Kuriyama S, Ishikawa $M$, Furu $M$, Ito $H$, Matsuda $S$. Malrotated tibial component increases medial collateral ligament tension in total knee arthroplasty. J Orthop Res 2014;32(12):1658-66. Crossref

13. Laskin RS, Beksac B. Stiffness after total knee arthroplasty. J Arthroplasty 2004;19(4 Suppl 1):41-6. Crossref

14. Figgie HE 3rd, Goldberg VM, Heiple KG, Moller HS 3rd, Gordon $\mathrm{NH}$. The influence of tibial-patellofemoral location on function of the knee in patients with the posterior stabilized condylar knee prosthesis. J Bone Joint Surg Am 1986;68(7):1035-40. Crossref

15. Shoji H, Solomonow M, Yoshino S, D'Ambrosia R, Dabezies E. Factors affecting postoperative flexion in total knee arthroplasty. Orthopedics 1990;13(6):643-9. Crossref

16. Lombardi AV Jr, Mallory TH, Fada RA, Hartman JF, Capps SG, Kefauver CA, Adams JB. An algorithm for the posterior cruciate ligament in total knee arthroplasty. Clin Orthop Relat Res 2001;392:75-87. Crossref

17. Singleton N, Nicholas B, Gormack N, Stokes A. Differences in outcome after cruciate retaining and posterior stabilized total knee arthroplasty. J Orthop Surg (Hong Kong) 2019;27(2):2309499019848154. Crossref

18. Zachwieja E, Perez J, Hardaker WM, Levine B, Sheth N. Manipulation Under Anesthesia and Stiffness After Total Knee Arthroplasty. JBJS Rev 2018;6(4):e2. Crossref

19. Katz MM, Hungerford DS. Reflex sympathetic dystrophy affecting the knee. J Bone Joint Surg Br 1987;69-B(5):797803. Crossref

20. Furia JP, Pellegrini VD Jr. Heterotopic ossification following primary total knee arthroplasty. J Arthroplasty 1995;10(4):413-9. Crossref

21. Schiavone Panni A, Cerciello S, Vasso M, Tartarone M. Stiffness in total knee arthroplasty. J Orthop Traumatol 2009;10(3):111-8. Crossref

22. Fox JL, Poss R. The role of manipulation following total knee replacement. J Bone Joint Surg Am 1981;63(3):357-62. Crossref

23. Ghani H, Maffulli N, Khanduja V. Management of stiffness following total knee arthroplasty: a systematic review. Knee 2012;19(6):751-9. Crossref

24. Desai AS, Karmegam A, Dramis A, Board TN, Raut V. Manipulation for stiffness following total knee arthroplasty: when and how often to do it? Eur J Orthop Surg Traumatol 2014;24(7):1291-5. Crossref

25. Bawa HS, Wera GD, Kraay MJ, Marcus RE, Goldberg VM. Predictors of range of motion in patients undergoing manipulation after TKA. Clin Orthop Relat Res 2013;471(1):258-63. Crossref

26. Gu A, Michalak AJ, Cohen JS, Almeida ND, McLawhorn AS, Sculco PK. Efficacy of Manipulation Under Anesthesia for Stiffness Following Total Knee Arthroplasty: A Systematic Review. J Arthroplasty 2018;33(5):1598-605. Crossref

27. Kalson NS, Borthwick LA, Mann DA, Deehan DJ, Lewis P, Mann C, Mont MA, Morgan-Jones R, Oussedik S, Williams FM, Toms A, Argenson JN, Bellemans J, Bhave A, Furnes O, Gollwitzer H, Haddad FS, Hofmann S, Krenn V. International consensus on the definition and classification of fibrosis of the knee joint. Bone Joint J 2016;98-B(11):1479-88. Crossref

28. Issa K, Pierce TP, Brothers A, Mclnerney VK, Chughtai M, Mistry JB, Bryant WW, Delanois RE, Harwin SF, Mont MA. What Is the Efficacy of Repeat Manipulations Under Anesthesia to Treat Stiffness Following Primary Total Knee Arthroplasty? Surg Technol Int 2016;28:236-41. https:// pubmed.ncbi.nlm.nih.gov/27042790/ 
29. Smith EL, Banerjee SB, Bono JV. Supracondylar femur fracture after knee manipulation: a report of 3 cases. Orthopedics 2009;32(1):18. Crossref

30. Pariente GM, Lombardi AV Jr, Berend KR, Mallory TH, Adams JB. Manipulation with prolonged epidural analgesia for treatment of TKA complicated by arthrofibrosis. Surg Technol Int 2006;15:221-4. https://pubmed.ncbi.nlm.nih. gov/17029180/

31. Cancienne JM, Gwathmey FW, Werner BC. Intraoperative corticosteroid injection at the time of knee arthroscopy is associated with increased postoperative infection rates in a large Medicare population. Arthroscopy 2016;32(1):90-5. Crossref

32. Court C, Gauliard C, Nordin JY. Technical aspects of arthroscopic arthrolysis after total knee replacement. Rev Chir Orthop Reparatrice Appar Mot 1999;85(4):404-10. https://pubmed.ncbi.nlm.nih.gov/10457561/

33. Encinas-Ullán CA, Rodríguez-Merchán EC. Arthroscopic treatment of total knee arthroplasty complications. EFORT Open Rev 2019;4(2):33-43. Crossref

34. Scranton PE Jr. Management of knee pain and stiffness after total knee arthroplasty. J Arthroplasty 2001;16(4):428-35. Crossref
35. Cregar WM, Khazi ZM, Lu Y, Forsythe B, Gerlinger TL. Lysis of Adhesion for Arthrofibrosis After Total Knee Arthroplasty Is Associated With Increased Risk of Subsequent Revision Total Knee Arthroplasty. J Arthroplasty 2021;36(1):339-44. e1. Crossref

36. Scuderi GR. The stiff total knee arthroplasty: causality and solution. J Arthroplasty 2005;20(4 Suppl 2):23-6. Crossref

37. Moya-Angeler J, Bas MA, Cooper HJ, Hepinstall MS, Rodriguez JA, Scuderi GR. Revision Arthroplasty for the Management of Stiffness After Primary TKA. J Arthroplasty 2017;32(6):1935-9. Crossref

38. Ries MD, Badalamente M. Arthrofibrosis after total knee arthroplasty. Clin Orthop Relat Res 2000;380:177-83. Crossref

39. Rutherford RW, Jennings JM, Levy DL, Parisi TJ, Martin JR, Dennis DA. Revision Total Knee Arthroplasty for Arthrofibrosis. J Arthroplasty 2018;33(7):S177-81. Crossref

40. Keeney JA, Clohisy JC, Curry M, Maloney WJ. Revision total knee arthroplasty for restricted motion. Clin Orthop Relat Res 2005;440:135-40. Crossref 